\title{
The Effect of Exergaming on Eye-Hand Coordination among Primary School Children: A Pilot Study
}

\author{
Ada Wai Wing Ma, Lily Qu \\ Department of Health and Physical Education, The Hong Kong Institute of Education, Hong Kong, China \\ Email: ama@ied.edu.hk
}

Received 19 April 2016; accepted 13 May 2016; published 17 May 2016

Copyright (C) 2016 by authors and Scientific Research Publishing Inc.

This work is licensed under the Creative Commons Attribution International License (CC BY).

http://creativecommons.org/licenses/by/4.0/

cc) (i)

\begin{abstract}
The aim of this study was to investigate the effectiveness of exergaming on improving Eye-Hand Coordination (EHC) among primary school children. Eighteen student volunteers joined this study who were arranged to play exergaming for thirty minutes three times a week during three months intervention. The result of Wilcoxon Signed-Rank test showed a significant decrease in time spent on Mirror Tracing Test (MTT), indicating a positive impact of exergaming on EHC among primary school children. In conclusion, it offers an alternative for education professionals in the school setting to integrate exergaming as an effective means to enhance students' EHC.
\end{abstract}

\section{Keywords}

\section{Exergaming, Eye-Hand Coordination, Physical Activity}

\section{Introduction}

Exergaming is a popular and thriving technology that allows players to use gross body movements to simulate physical activities on screens, such as dancing and boxing. In the past two decades, various kinds of exergames have been introduced and perfected. In the late 1990s, Dance Revolution using pressure-sensitive footpads to connect players' body movements improved the interface of exergames. In 2006 Nintendo Wii hit the market using wireless remote held in hands to allow upper body movements especially arms. In 2010 Microsoft released Kinect using optical sensing to finally track whole-body movements. Playing exergames have not only been considered as one option of entertainments but also been investigated as a tool to improve health. Major contributions of exergames to health promotion are summarized as follows: 1) increasing energy expenditure and con- 
tribute to moderate to high intensity physical activity (Adkins, Brown, Heelan, Ansorge, Shaw, \& Shaw, 2013; Sween, Wallington, Sheppard, Taylor, Llanos, \& Adams-Campbell, 2014; Wu, Wu, \& Chu, 2015; Gao, Chen, \& Stodden, 2015); 2) being perceived as enjoyable, motivating, and reinforcing exerciseby adding competition and group play features (Best, 2013); and 3) promoting postural stability and correction for rehabilitation (Sheehan \& Katz, 2012; Sims, Cosby, Saliba, Hertel, \& Saliba, 2013).

One of the significant contributions of exergaming to health is perhaps the enhancement of eye-Hand Coordination (EHC). The coordinated processing visual input with the proprioceptive guide of hands while reaching and grasping is known as eye-hand coordination. EHC plays a pivotal role in many kinds of sports, especially in ball games which require a lot of reaching and catching. It has been documented that children with better EHC generally have a better body image and more likely to participate in various kinds of sports, but EHC is not found to be associated with percent body fat or amount of physical activities (Telford, Cunningham, Telford, Olive, Byrne, \& Abhayaratna, 2013). A study by Wicks, Telford, Cunningham, Semple, \& Telford (2015) showed that EHC became better with a growing age in 8 to 16 years old children, and it was modified by the difficulty of the task. Boys' EHC were better than girls' at the age of eight. Specifically, throw and two-handed catch proficiency developed earlier and faster than throw and one-handed catch in both sexes. The underlying mechanism of EHC performance and developments has been vastly investigated, but few studies to our knowledge dedicate to assess the impact of physical activities on EHC, and nearly none focuses on the effectiveness of exergaming on improving EHC. To fill the literature gap, the aim of the current study thus is to investigate whether playing exergames can contribute to the developments of EHC among primary school children.

\section{Methods}

\subsection{Trial Design}

The study assesses the effect of exergaming on EHC of a group of primary school students, in which no control group is involved.

\subsection{Subjects}

Convenience sampling was chosen for this study as the researchers had connection with school teachers and it facilitated easy collection of data. The study subjects were P4-P6 student volunteers in a primary school. Ethical approval was acquired from the Human Research Ethics Committee of The Hong Kong Institute of Education. Consent forms were collected from students' parents and school as well. After excluding students with medical history of heart disease, epilepsy or ones in post-op, the rest were recruited on the name lists. Every $4^{\text {th }}$ student on the name list was chosen until there were total eighteen study subjects. The current sample size in the study was determined by the availability of subjects, the capacity of research team and also the study design.

\subsection{Interventions}

A pre-intervention lesson was given to the study subjects in which elite athletes delivered some physical education and good health concepts. After the lesson, a familiarization session was set for the subjects to experience interactive physical-activity exergames. During intervention phase, subjects were administered to play exergaming for 30 minutes three times a week for three months. Each subject had three choices of different exergames-Sport Rival \& Boom Ball, Shape Up and Just Dance 2015, each subject had the same amount of time for each game during the three months period to achieve even practice.

\subsection{Outcome Measures}

The study adopted Mirror Tracing Test (MTT) to assess eye-hand coordination. Pre-test practice was required. Each student took MTT for two times, the first time was before the pre-intervention lesson, the second time was after the three months intervention. Finishing time for each subject was recorded.

\subsection{Statistical Analyses}

Wilcoxon signed-rank test was used to compare time and score differences between pre-and post-intervention. All statistical tests were performed in SPSS (version 22.0, SPSS Inc., Chicago, IL, USA). 


\section{Results}

There were total eighteen students in our study and they all completed the MTT tests.

During three months intervention, study subjects were arranged to play exergames for 23 times. Attendance ranged from $80 \%-100 \%$. At the time of admission, the mean age was 11.5 with a standard deviation of 1.7 (Table 1). MTT was done three times for each subject, one time MTT result was calculated by adding mistakes times two to time spent at finishing the test, then Mean MTT was calculated by taking the average of three times’ results.

At project completion, a significant increase was found between pre- and post-intervention body height, as well as a significant decrease between pre-and post-intervention Mean MTT (Table 2) with an effect size of 0.67.

\section{Discussion}

The finding suggests that playing exergames contribute to the developments of EHC among primary school children which resonate with several previous studies. Victoria, Alexandru, \& Florentina (2010) found that EHC in third form pupils could be enhanced by physical activities. Another study by Halewyck, Lavrysen, Levin, Boisgontier, Elliott, \& Helsen (2014) also indicated that EHC was influenced by both age and physical activity level since it was observed that not only in elderly, sedentary young adults also showed typical age-related hand movement adaptations.

To transfer the knowledge of the effectiveness of exergaming on EHC in school settings, it is proposed that a physical education lessoncan adopt the following exergame routine to optimize EHC development among school children, that is, playing exergaming for 30 minutes three times a week in which each subject has choices of different exergames to promote game fun with the same amount of time for each game to achieve even practice. Such a routine can be taught in school during physical education classes and exported beyond classroom when children could play exergaming at home. It is equally important to gain the support from physical education teachers in schools to integrate exergaming as an effective mean to enhance students’ EHC (Zhang et al., 2012). Physical education teachers are the ones who provide the children with the games in classes, the ones who decide the amount of time devoted to these games, and most often set the example of a physically active lifestyle (Lin \& Zhang, 2011). While empirical research evidence has been limited, many school physical education teachers may not be opposed to offer exergaming as a means to promote EHC among school children as itshould simply be thought of as one component that could be a more enjoyable medium to transition to more physical activity.

Utilizing exergaming to promote EHC seems successful; however, there are some challenges that have to be faced. One of the most common challenges is the costing to implement, specifically if the intervention is conducted within an educational setting due to budget concerns.

This project is a pilot study which carries a numbers of limitations: 1) the sample size was small, thus a low power (0.62) was achieved; 2) the relationship between each different exergame and the improvement of EHC

Table 1. Baseline characteristics.

\begin{tabular}{ccc}
\hline & Mean & SD \\
\hline Age (y) & 11.5 & 1.7 \\
Body Height (cm) & 153.9 & 115 \\
Body Weight (kg) & 46.1 & 12.6 \\
Mean MTT & 272.1 & 249.6 \\
\hline
\end{tabular}

Table 2. Test statistics between pre-and post-intervention.

\begin{tabular}{cccc}
\hline & Mean difference & Z statistic $^{\text {p-value }}$ & \\
\hline Body Height $(\mathrm{cm})$ & 1.25 & -2.01 & $0.04^{*}$ \\
Body Weight $(\mathrm{kg})$ & -0.56 & -0.87 & 0.39 \\
Mean MTT & -148.13 & -2.64 \\
\hline
\end{tabular}

${ }^{1}$ Wilcoxon signed-rank Test was used to determine $\mathrm{p}$-values; ${ }^{*} \mathrm{p}<.05 ;{ }^{* *} \mathrm{p}<.01 ;{ }^{* *} \mathrm{p}<.001$. 
was not studied and there might be a different effect of each game on EHC development, while in our study all exergames were considered as a whole; and 3) the study design did not involve a control group, so it was unknown whether factors other than intervention programme might affect the EHC development.

\section{Conclusion}

The major finding of the current study reveals that exergaming among young children contributes to EHC development. Playing exergames could become one of the most popular, engaging, and health-promoting school assignments of the twenty-first century. Exergames can promote children's EHC development and enhance their exercise motivation by enjoyment, leading to more physical activities. It can be a good alternative for EHC enhancement and addition to traditional physical activity and sports in children. Future directions for research should also include the influence of exergaming on population of special education needs in schools.

\section{Acknowledgements}

The authors would like to thank Chan Cho Kwan, Cheung Hing Nam, Cheung Lok Yi, Lau Chi Pang, Leung Sin Ting, Wong Bik Shing, Wong Hoi Kei and Yuen Tin Man for their support in data collection.

\section{References}

Adkins, M., Brown, G. A., Heelan, K., Ansorge, C., Shaw, B. S., \& Shaw, I. (2013). Can Dance Exergaming Contribute to Improving Physical Activity Levels in Elementary School Children? African Journal for Physical, Health Education, Recreation and Dance, 19, 576-585.

Best, J. R. (2013). Exergaming in Youth, Effects on Physical and Cognitive Health. Zeitschrift Fur Psychologie, 221, 72-78. http://dx.doi.org/10.1027/2151-2604/a000137

Gao, Z., Chen, S., \& Stodden, D. F. (2015). A Comparison of Children’s Physical Activity Levels in Physical Education, Recess, and Exergaming. Journal of Physical Activity and Health, 12, 349-354. http://dx.doi.org/10.1123/jpah.2013-0392

Halewyck, F. V., Lavrysen, A., Levin, O., Boisgontier, M. P., Elliott, D., \& Helsen, W. F. (2014). Both Age and Physical Activity Level Impact on Eye-Hand Coordination. Human Movement Science, 36, 80-96. http://dx.doi.org/10.1016/j.humov.2014.05.005

Lin, L., \& Zhang, T. (2011). Playing Exergames in the Classroom: Pre-Service Teachers’ Motivation, Passion, Effort, and Perspectives. Journal of Technology and Teacher Education, 19, 243- 260.

Sheehan, D. P., \& Katz, L. (2012). The Impact of a Six Week Exergaming Curriculum on Balance with Grade Three School Children using the Wii FIT $+{ }^{\mathrm{TM}}$. International Journal of Computer Science in Sport, 11, 5-22.

Sims, J., Cosby, N., Saliba, E. N., Hertel, J., \& Saliba, S. A. (2013). Exergaming and Static Postural Control in Individuals with a History of Lower Limb Injury. Journal of Athletic Training, 48, 314-325. http://dx.doi.org/10.4085/1062-6050-48.2.04

Sween, J., Wallington, S. F., Sheppard, V., Taylor, T., Llanos, A. A., \& Adams-Campbell, L. L. (2014). The Role of Exergaming in Improving Physical Activity: A Review. Journal of Physical Activity and Health, 11, 864-870. http://dx.doi.org/10.1123/jpah.2011-0425

Telford, R. D., Cunningham, R. B., Telford, R. M., Olive, L. S., Byrne, D. G., \& Abhayaratna, W. P. (2013). Benefits of Early Development of Eye-Hand Coordination: Evidence from the LOOK Longitudinal Study. Scandinavian Journal of Medicine and Science, 23, e263-e269. http://dx.doi.org/10.1111/sms.12073

Victoria, G. D., Alexandru, S., \& Florentina, H. (2010). Eye-Hand Coordination in Third Form Pupils. Ovidius University Annals, Series Physical Education \& Sport/Science, Movement \& Health, 10, 688-691.

Wicks, L. J., Telford, R. M., Cunningham, R. B., Semple, S. J., \& Telford, R. D. (2015). Longitudinal Patterns of Change in Eye-Hand Coordination in Children Aged 8 - 16 Years. Human Movement Science, 43, 61-66. http://dx.doi.org/10.1016/j.humov.2015.07.002

Wu, P.-T., Wu, W.-L., \& Chu, I.-H. (2015). Energy Expenditure and Intensity in Healthy Young Adults during Exergaming. American Journal of Health Behavior, 39, 556-561. http://dx.doi.org/10.5993/AJHB.39.4.12

Zhang, T., Solmon, M. A., \& Gu, X. (2012). The Role of Teachers' Support in Predicting Students' Motivation and Achievement Outcomes in Physical Education. Journal of Teaching in Physical Education, 31, 329-343. 